Issue 1/2018

\title{
UNIVERSITY-INDUSTRY PARTNERSHIPS FOR INNOVATION: SRI LANKAN EXPERIENCES
}

\author{
R. N. WEERASINGHE ${ }^{1}$, A. K. W. JAYAWARDANE ${ }^{2}$ \\ ${ }^{1}$ Senior Lecturer, Faculty of Management Studies and Commerce, University \\ of Sri Jayewardenepura, Nugegoda, 10250, Sri Lanka, Tel: +94718130843, \\ Fax: +94112803653, Email: rukmal@sjp.ac.lk \\ ${ }^{2}$ Senior Professor, Department of Civil Engineering, Faculty of Engineering, \\ University of Moratuwa, Katubedda, 10400, Sri Lanka, Tel: +94777688865, \\ Fax: +94112650622, Email: anandaj@uom.lk
}

\begin{abstract}
The university sector in the national innovation system (NIS) is considered as one of the key players, which links new knowledge with the industry for the purpose of diffusing new knowledge for economic and social benefits through commercialization of products, services, processes and other artefacts. This paper inquires the role of Sri Lankan universities in the innovation process by paying special attention on the strength of universityindustry linkages. Responses from the industrial sector were obtained through a surveys and interviews with respondents.

Data presented and analyzed through descriptive statistics using summery statistics and figures. Social Network Analysis (SNA) was employed to determine the strength of the networking relationship among the universities and the firms' qualitative data were analyzed employing the method of content analysis.

The study revealed a positive trend in the higher education sector towards performing effective role in the future towards innovation. However, it was evident that these relationships have still remained very weak. The industrial sector remains inward oriented with little intention to innovation, while universities still prioritize their traditional teaching role in higher education.
\end{abstract}

Keywords: innovation; university-industry relationships; NIS; networking; Sri Lanka.

JEL Classification: $\mathrm{O}_{32}$ 


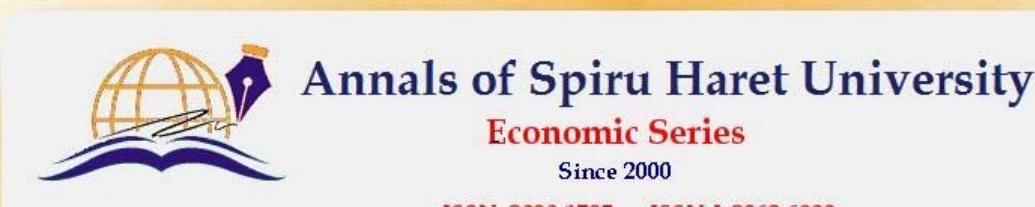

ISSN: 2393-1795 ISSN-L:2068-6900

\section{Issue 1/2018}

\section{Introduction}

The systematic view of innovation at the national level has attracted much attention from the latter part of the 1980s and it is a popular research theme all around the world at present. Freeman (1987), Lundvall (1992) and Nelson (1993) are the renowned early contributors to the perspective of NIS. This concept is focused on the inter-relationship and inter-dependencies among the major actors of national innovation system that work to create, develop and diffuse new knowledge mainly for the commercialization of new products, services and processes. Government and government institutions, universities and research institutions, and the firms that operate in different industries are considered as the three main actors and they are expected to establish an inter-relationship among themselves towards better innovative performance as explained in NIS literature.

Traditionally, universities were responsible for providing facilities for higher education mainly and engaging in basic research activities, resulting in being known as teaching facilities. Even at present, this remains unchanged in many developing countries. Moving from the traditional teaching and researching functions, the role of the universities to promote innovation in knowledge-based societies has been emphasized in the Triple Helix model [Etzkowitz \& Leydesdroff, 2000]. These authors stressed the role of universities in technology and knowledge transfers through their direct contribution to industry to create marketable products and services. Chesbrough (2006) further confirms this idea with the open innovation model. The open innovation model highlights the importance of the knowledge spill in and spill over for the successful innovations, hence encourage firms to maintain successful linkages with the innovation actors of the economy such as universities and other R\&D firms for the creation and commercialization of innovation successfully.

As a result, there is a growing need to link university activities with the interdisciplinary approaches of problem solving in the industries through a new institutional approach, as one of the major cornerstones of modern innovation systems [Galli \& Teubal, 1997 and Perkmann \& Walsh, 2007]. Hargadon (2002) has discussed the importance of linking the knowledge created through research and development activities to the introduction of innovation by the industry. The practices such as university-industry collaborative research centres, contract research and consulting [Perkmann \& Walsh, 2007], facilitating students to acquire practical experience [Klevorick et al., 1995] and sharing university infrastructure with industry for developing innovations [Galli \& Teubal, 1997] are some of the new roles suggested for the university system for mutual benefits. Munari and Toschi (2011) have emphasized that there is a high possibility to find initial capital 26 


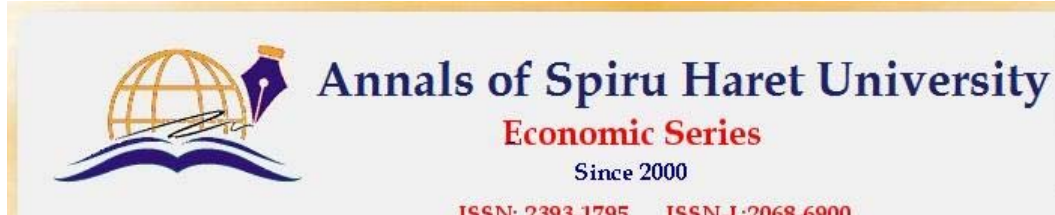

ISSN: 2393-1795 ISSN-I*2068-6900

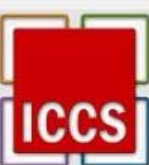

Issue 1/2018

through venture capital firms for a new start up business idea if it is a result of a university-industry collaborative research work. Therefore, De Silva et al. (2012) have studied the entrepreneurial role of academics in Sri Lanka paying special attention to universities specialized in science and technology and found that the traditional role of the university academics is dramatically changing. Accordingly, more than $50 \%$ academics of the university system in their sample had already engaged with entrepreneurial activities, even starting up their own ventures while some are still inward oriented single role players.

This is an attempt to review relationships existing between universities and firms and the role of universities in the NIS of Sri Lanka from the integrative and collaborative perspectives. In addition, this study has the intention to critically review the role of universities in Sri Lanka paying attention on networking relationships with industries. It emphasizes the importance of stronger interactions with the business sector through the establishment of interface units such as incubators, business support services and consulting units, and joint scientific research and technology development programs. Further, the role of universities in terms of collaborating with the government and related institutions towards making policies, rules and regulations is also focused upon.

\section{University system in Sri Lanka}

The university system in Sri Lanka has been restructured through the No. 16 University Act of 1978, vesting the power to the University Grants Commission (UGC), as an apex body of the university system, to plan and coordinate university education, allocate funds to Higher Educational Institutions (HEIs), maintain academic standards, regulate and administer HEIs and handle admission of students to HEIs. There are 15 national universities and 3 campuses directly governed and funded by the UGC and Sri Lankan government. Although the state universities are dominant in the higher education sector in Sri Lanka, several private higher education institutions have also been incorporated and started their operations in the recent past, with the support of Sri Lankan government's new policy.

As presented in the UGC statistics book (2015), the expenditure in university education as a percentage of government expenditure was 1.42 in 2012 and it had been raised up to 1.77 in 2015 . The average student's per capita cost in university education was Rs. 246,663 in 2012, and it had been increased to Rs. 384,612 in 2015. Total employment in the entire state university system was 17,172 in 2015.

The student-teacher ratio in the Sri Lankan university sector was 17.8 as in 2015. Total number of new admissions in state university education was 25,643 in 


\section{Issue 1/2018}

2015. Table no. 1 shows the statistics of university admissions based on the main four streams of the courses as categorized by the UGC. In the same year, 29,545 students have graduated in their first degrees.

Table no. 1. Students Allocation in Academic Years 2013/2014 and 2014/2015

\begin{tabular}{|l|r|r|}
\hline \multirow{2}{*}{ Subject Stream } & \multicolumn{2}{c|}{ Admission Year } \\
\cline { 2 - 3 } & $\mathbf{2 0 1 3 / 2 0 1 4}$ & \multicolumn{2}{|c|}{$\mathbf{2 0 1 4 / 2 0 1 5}$} \\
\hline Arts & 8,227 & 8,617 \\
\hline Commerce & 5,225 & 5,299 \\
\hline Physical Sciences & 5,280 & 5,287 \\
\hline Biological Sciences & 6,376 & 6,316 \\
\hline Other & 92 & 124 \\
\hline Total & $\mathbf{2 5 , 2 0 0}$ & $\mathbf{2 5 , 6 4 3}$ \\
\hline
\end{tabular}

Source: Survey Data, 2015

Table no. 2. Teachers in the State Universities of Sri Lanka in 2015

\begin{tabular}{|l|c|c|c|}
\hline \multirow{2}{*}{ University } & \multicolumn{3}{c|}{ Number of Teachers } \\
\cline { 2 - 4 } & Professors & $\begin{array}{c}\text { Senior } \\
\text { Lecturers }\end{array}$ & Lecturers \\
\hline Colombo & 107 & 263 & 165 \\
\hline Peradeniya & 135 & 413 & 219 \\
\hline Sri Jayewardenepura & 85 & 314 & 140 \\
\hline Kelaniya & 119 & 283 & 144 \\
\hline Moratuwa & 45 & 189 & 101 \\
\hline Jaffna & 32 & 197 & 160 \\
\hline Ruhuna & 73 & 250 & 151 \\
\hline Eastern & 5 & 118 & 69 \\
\hline South eastern & - & 77 & 49 \\
\hline Rajarata & 9 & 86 & 108 \\
\hline Sabaragamuwa & 10 & 113 & 75 \\
\hline Wayamba & 12 & 76 & 63 \\
\hline Uva Wellassa & - & 38 & 60 \\
\hline Visual and performing arts & 11 & 55 & 42 \\
\hline Open university & 21 & 145 & 130 \\
\hline
\end{tabular}

Source: University Statistics Book, 2015 


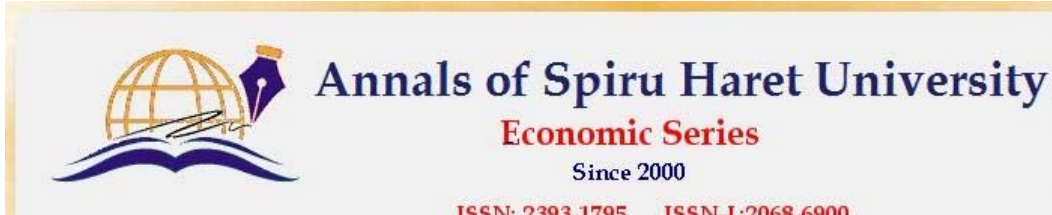

ISSN: 2393-1795 ISSN-I -2068-6900

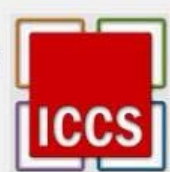

Issue 1/2018

Highly qualified and experienced academic staff employed in the state university system in Sri Lanka is considered as a major strength. Teaching staff refers to the lecturers, senior lecturers and professors. Table no. 2 presents the composition of academics in universities in 2015.

The total number of teaching staff in higher educational institutions reveals that there were 687 professors, 2,756 senior lecturers and 1,756 probationary lecturers in 2015. The grand total was 5,199 academic members in the system. These data prove that the university education sector in Sri Lanka is very strong and capable of producing new knowledge.

\section{The role of Universities in NIS}

The attention on the role of universities in the NIS of a country has been continuously increased. This is a result of popularization of findings of university research activities in the processes of development of new products, services and technologies introduced by the industry. This has increased the importance of multiand interdisciplinary research and development. Further, it has strengthened interrelations for the purpose of industrial applications of basic research activities. The early research on NIS concerned technological innovation process as the core on firm activities in the beginning of 1990s. According to Lundvall (2010), early research models attempted to measure firms' innovation performance in terms of new products developed, linkages maintained between firms and other actors in the NIS. This also includes the capability of a firm to absorb technologies developed by knowledge creators. In recent scholarly works, the specific role played by other actors, such as governments and universities is also emphasized. Government role is defined in relation with creating policy incentives, while the universities role has been linked to conducting research. Therefore, the triple actors' model named "Triple Helix" emerged to give a deeper understanding on the relationships among these actors [Etzkowitz \& Leydesdorff 2000]. This model opened up an alternative avenue for NIS studies by addressing knowledge commercialization though licensing, as well as through starting spinoff companies linked to the universities. The traditional role in teaching and research of the universities was considered as their first priority. Transferring the knowledge to industries and society began to be considered as the next priority. The third priority was the stream combination of first and second priorities. These three modes of streams require specific policies and resources to ensure the effective functioning for a strong NIS.

As a part of university role it needs to develop models, marketable ideas and also transfer those effectively to the industry for commercialization. Triple Helix 


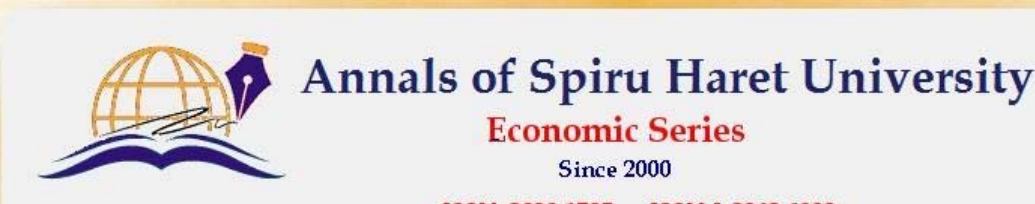

ISSN: 2393-1795 ISSN-L:2068-6900

\section{Issue 1/2018}

concept emphasized the necessity of university-industry-government interactions for these fruitful modes of streams. Identifying the role of universities in the process is a bit difficult task. However, it can be identified as engagement in joint research activities together with industry firms, transferring new products to industry, sharing infrastructure, mobility of high-trained research and development personnel and visiting lecturing for industry etc. Universities distribute knowledge via teaching and improve the stock of human capital. Apart from that, university broaden the knowledge via researching. Without satisfying the above, they need to transfer the generated knowledge to society by collaborating with the industry. This category of activities is the results of the first two functions that are education and research. Third stream has not yet been a core function in the same way as the first two streams, but an increasing attention has been given to this aspect. Today, universities have to play an active role in transferring knowledge, science and technology development to useful innovations all the times. In the global context, all national, regional and local levels are motivating the "third stream", which is describing the collaborative role of universities and industries. Currently, university involvement for the innovationbased development is much more appreciated than earlier [Geuna \& Muscio, 2009].

Eminent universities in the world have shown their interest in engaging in all three missions. They are trying to excel, as well as to exploit and create strong connection among those missions that are teaching, conducting research and technology transfers [Van Looy et al., 2004]. The role of modern universities has been recognized as to create and introduce potential innovations for the requests of the societies. This requires engaging in basic research activities mainly since those are characterized by high uncertainties in market and technological successes and long-term impact visibility. Hence, there is a tendency that private investors are trying to stay away from basic research. It has become a key function of the universities and public research institutes generating science-based knowledge as a result of the reluctance of the private sector firms. In addition to the formal relationships, which can be recognized easily, there are countless informal relationships that relate to innovation processes, knowledge transfer, and industrial science-based networks, whether personal or organizational. Knowledge exchange among firms and research institutes emphasizes the importance of informal relationships and flows of human capital. According to Chesbourgh (2003), science and technology laboratories from universities need to be available for open innovation projects, which are closely monitored by companies who engaged in those research and development activities. Researches with more academic orientation reveal appropriate methodologies required frameworks that can be 


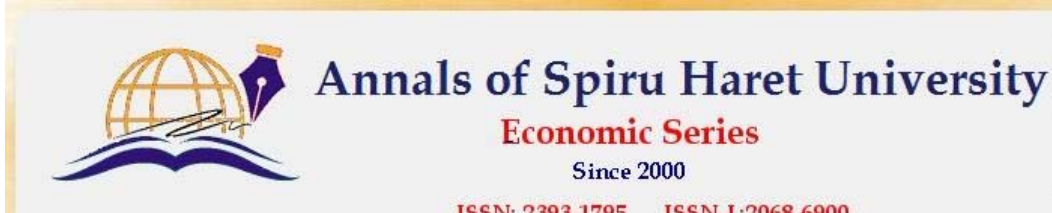

ISSN: 2393-1795 ISSN-L-2068-6900

Issue 1/2018

utilized in applied researches engaged by firms in their own R\&D facilities. Depending on the findings of scientific researches, firms can develop a better foundation for their technological landscapes in search of inventions for the future. Based on this foundation, they are allowed to foresee future innovations, evaluate those from different aspects and transform those to successful commercialized innovation [Rosenberg, 1990; Fleming \& Sorenson, 2004].

Many countries are searching for better policies to create strong and fruitful collaborations among universities and industry. This policy formations and applications have created a value for university-based research and hence, transferred those to successful innovation boosting economic performances [Cohen \& Noll, 1994]. Accordingly, those policy initiatives have created common premises for the universities to be able to help the industry-led innovation. Triggering potential deliverable innovations for commercialization through this support and sharing mechanism is the main focus in this research paper.

\section{NIS in developing countries}

Recent studies have addressed the condition of NISs in developing countries. Accordingly, there is a limited presence of required institutions in many developing countries [Intarakumnerd et al., 2002]. Further, they have pointed out that industrial innovation in many developing countries is highly informal and unsystematic. Innovations in those countries are not the results of formally articulated through conscious engagements in R \& D activities. Subsequently, it has been emphasized that the dominant cultural patterns of these developing countries do not appreciate the importance of scientific knowledge and technological innovation. Hence, it is concluded that NISs of developing countries are less developed. These systems have not much contributed for the institutional and technological properties required for modern economic growth. It is necessary to understand the way in which the innovation process is operating with current economic position and the changes expected within the country. These should be studied in line with the context of the economic development. The studies in NISs should be interconnected with the country's economic and institutional development and growth. Newly industrialized countries such as South Korea, Taiwan have paid attention to strengthening their NIS and were able to acquire a great economic growth. The developing countries need to pay considerable attention on enhancing their strategic capacity for innovation in the government level, institutional level, educational level etc. Comparing major inputs of the NISs in developing countries with those of developed countries, one should note that capital accumulation, 


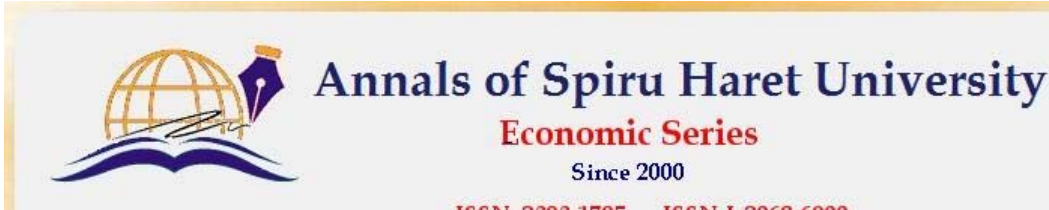

ISSN: 2393-1795 ISSN-L:2068-6900

\section{Issue 1/2018}

which facilitates knowledge creation and learning, is significantly higher in developed context, thus resulting in strong NISs. It can be concluded that innovation is the results of the collaboration between societal activities and findings of the science and technology initiatives. However, innovation does not count only as a result of technology creativeness. Most specific regional, social and economic factors affect effective innovations that need to be developed within countries. Therefore, the understanding of innovation and NIS diverges from place to place. The more the developing countries need to fill this gap existing in the NISs learning from developed, newly industrialized countries, and the more they need to grasp the benefits of increased economic performances.

\section{Methodology}

This study employed mix methodology to understand prevailing network relationships among the industry and the university sector in Sri Lanka. First survey was conducted to collect data from industrial sectors by means of structured, as well as open-ended questions to reveal their attachment to the university sector towards innovative activities in their organizations. According to the database available in Department of Census and Statistics of Sri Lanka, 280 SMEs were selected randomly from 8,734 recorded establishments in the Western Province of Sri Lanka. SMEs have been selected for study because many inclusive innovations appear in this informally limited resource sector in every economy. The survey instrument - the questionnaire - used in the study was developed based on innovation surveys conducted by the European Union (CIS), African countries (NEPAD) and the National Science Foundation (NSF) in Sri Lanka with the required modification to reveal network relationships maintained by the SMEs with other innovative actors. The data obtained through the survey were confirmed and tested through the face-toface type focus discussions conducted with 15 SME owners.

The second survey was designed to collect data from the university point of view. All the representatives from different universities, faculties, study departments and units were considered as a unit of analysis of the study. The deans of faculties and the heads of departments in the government universities in Sri Lanka were included in the survey population. There are 15 national universities with 80 faculties, 3 campuses and 494 academic departments in the entire university system and all were taken as the sample of this study. At the initial stage, a questionnaire was sent to all the deans of the faculties and heads of departments both via mail and email and was followed by extensive assistance and guidance given by the data collection team through telephone discussions, appointments or meeting et cetera. 

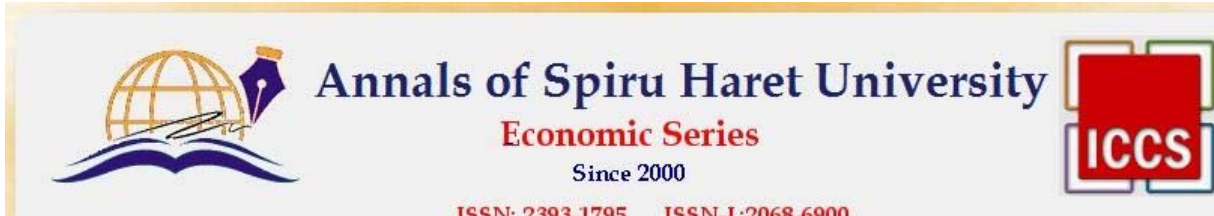

ISSN: $2393-1795 \quad$ ISSN-L-2068-6900

Issue 1/2018

Amidst time limitations and non-responsiveness, there were 104 responses, at the response rate of 18 per cent, from 24 Deans of faculties, 77 heads of departments, which was sufficient to the analysis. Two responses remained unidentified due to insufficient information.

In addition to the second survey conducted, the role of universities in promoting innovations was revealed through in-depth interviews conducted with university Vice Chancellors and high officials in the University Grants Commission. Seven Vice Chancellors were interviewed out of fifteen in the Sri Lankan state universities. A pre-prepared interview guide was used to ask open-ended questions and responses were written and recorded appropriately. The interviews lasted more than an hour to allow free and real disclosure of ideas about the contribution of the university sector to promoting innovations in the company. UGC statistics, published periodicals and universities' web pages were accessed as secondary data sources.

Data were analyzed through both quantitative and qualitative techniques. Mainly, the survey results were tabulated and analyzed through the methods suggested in descriptive statistics, with the help of the Statistical Package for Social Sciences, 22.0 version. This study has limited its data presentation and analysis only to reveal the networking relationship between the university sector and the industry represented in the sample. Qualitative data were analyzed through methods such as critical reviewing and content analysis to make a realistic picture on the partnership between two sectors concerned herewith.

Data from the faculties and departments in the Sri Lankan university system were analyzed to reveal their existing relationships with other universities, science and technology research institutions and the firms in the industry and also to illustrate and measure the strength of relationships using Social Network Analysis (SNA), a powerful method to image the social realities. For the purpose of summery calculations and drawing graphs, the SNA, NodeXL version 1.0.1.350, user friendly software was used.

\section{Results of the study}

First Survey: As a result of personal involvement in the data collection process, 145 completed questionnaires were collected in the first survey of the study. The size of the sample was sufficient, as mentioned in a similar World Bank study (2009), with the sample size for a large population of 120 and was rated $7.5 \%$ accurate and $90 \%$ confidence. Even though there were 145 completed survey questionnaires, 25 questionnaires had to be removed from the analysis, as these respondents have not provided any information about the firms' attachments and linkages with the 


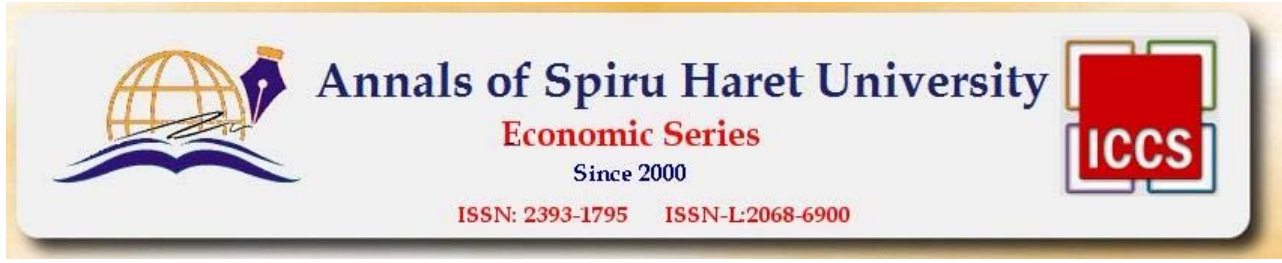

Issue 1/2018

university system. The sample was consisted with 120 responded firms distributed in four main industries as in the planned population frame. Namely, they are manufacturing of food products and beverages; manufacturing of textiles; manufacturing of wearing apparel, dressing and dying; and manufacturing of rubber and plastic products. The main four industries contributing to the GDP of the country were concerned to design the sample in the Western Province of Sri Lanka. There were fifty-six firms engaged in manufacturing food products and beverages, while twenty-eight firms operating in wearing apparel industry. There were fifteen firms engaged in manufacturing rubber and plastic products and sixteen firms were engaged in manufacturing textiles. The remainders (five firms) were undertaking their business in other related manufacturing industries such as manufacturing wood products and furniture, and manufacturing food processing machinery and equipment.

To address the main objective of the study, the responses were summarized and it was discovered that just only 18 organizations (out of 120) had some kind of relationship with the university sector. All other 102 organizations revealed that they do not have any kind of relationship with the formal university sector in Sri Lanka. It seems that these organizations are staying far away from the university system and 35 organizations clearly mentioned that they do not have an understanding about the university sector and the support, which can be obtained from the university sector for promoting innovations within their firms. Further, it was understood that they believe that the university is responsible for just producing graduates and their graduates match the large organizational requirements, but not those of the SMEs. However, the 18 organizations that have good relationships with universities showed their interest in strengthening their ties for further improvements of their products and processes through innovative solutions.

The importance of the university support lies in seven areas, namely (a) conducting research activities for the firm, (b) providing required training, (c) sending resource persons for in-house training organized by the firm, (d) providing opportunity to participate in education programs conducted by the universities, (e) allowing to use university laboratory facilities and consultancy for R\&D activities, (f) providing infrastructure facilities such as office spaces, library, and (g) providing management consultancy. Table 3 presents the responses of the firms obtained in a Likert scale on the importance of university facilitation and support in the specified seven key areas.

Irrespective of the present level of relationships maintained, the respondents were advised to provide responses for the above facilitation and support services that can be provided by the university sector. Figures 1 to 7 show the percentages of responses shown in Table no. 3. 
Issue 1/2018

Table no. 3. Importance of Facilitation and Support by Universities

\begin{tabular}{|l|c|c|c|c|c|}
\hline \multirow{2}{*}{ Facilitation or Supporting Program } & \multicolumn{5}{|c|}{ Degree of Importance } \\
\cline { 2 - 6 } & $\mathbf{1}$ & $\mathbf{2}$ & $\mathbf{3}$ & $\mathbf{4}$ & $\mathbf{5}$ (High) \\
\hline A. Conducting R\&D activities & & & & \\
\hline B. Conducting programs in the universities & 53 & 5 & 6 & 9 & 27 \\
\hline C. Invite resource persons for training programs & 54 & 8 & 7 & 12 & 17 \\
\hline D. Participating in the academic programs & 59 & 10 & 3 & 8 & 18 \\
\hline E. Providing technical and laboratory support/ advice & 48 & 7 & 9 & 10 & 25 \\
\hline F. Providing infrastructure support & 50 & 10 & 4 & 9 & 22 \\
\hline G. Providing management consultancies & 50 & 11 & 8 & 6 & 22 \\
\hline
\end{tabular}

Source: Survey Data, 2014

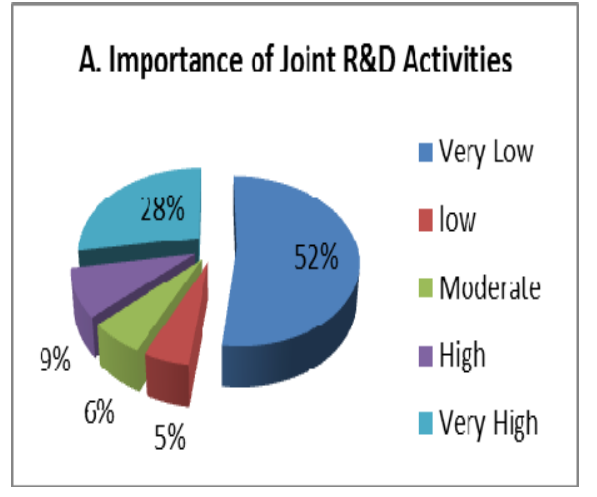

Figure no. 1. Importance of joint $R \& D$

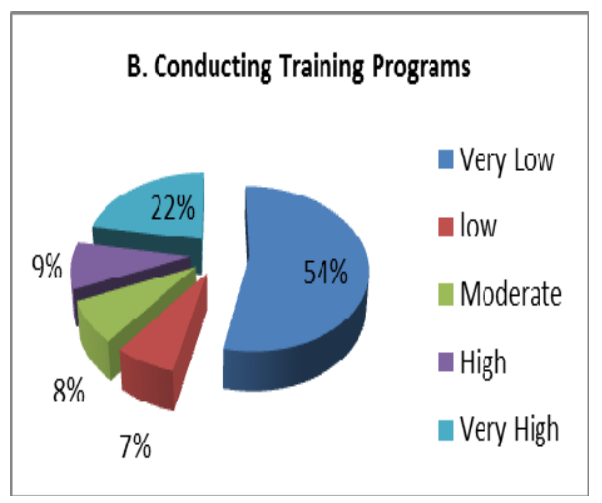

Figure no. 2. Conducting training program

According to the presented data in the above graphs and Table 3, the answers of the firm confirm that the importance of the facilities and the support given by the university system for the innovation and the development of the business has been recorded as very low. Percentages for the importance of the university facilitation and support are shown in graphs and prove that it varies in between $49 \%$ and $60 \%$ in the 'very low' rankings for all seven areas tested. This perception of the respondents is mainly motivated by the fact that they are unaware of the university's role in strengthening innovation in the country. However, there are considerable responses out of the rest of the Likert measurements for the importance of these university facilitation and support as perceived by the respondents in the 'very high' category. This demonstrates that firms that have relationships with universities perceive these seven facilitations and support offered by the university sector as being of the utmost importance for promoting 

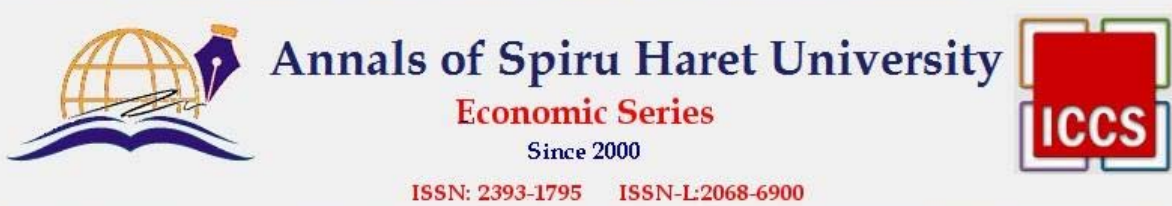

ISSN: 2393-1795

ISSN-L:2068-6900

\section{Issue 1/2018}

innovation within the firm. Responses for the 'very high' category spread from $18 \%$ to $28 \%$ of the respondents. These two responses on the importance of the university facilitation and support, i.e. 'very low' and 'very high', together count $73 \%$ to $80 \%$ for all seven items provided. Therefore, it seems that the respondents did not pay too much attention to the other three options (low, moderate and high), which led to a conclusion based on the frequency of the two extreme responses.

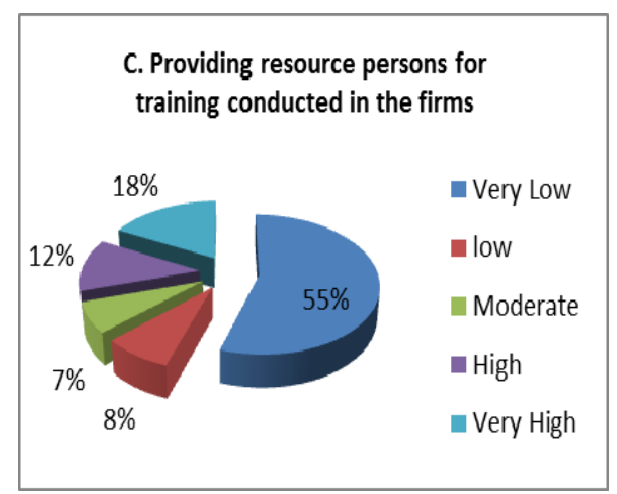

Figure no. 3. Providing resource persons for training conducted in the firm

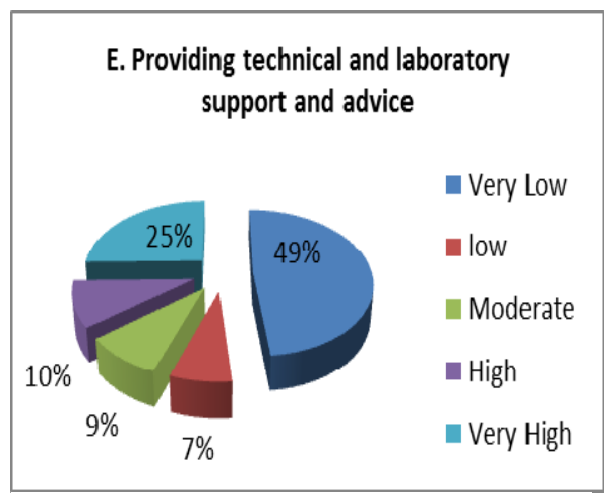

Figure no. 5. Providing technical and laboratory support and advice

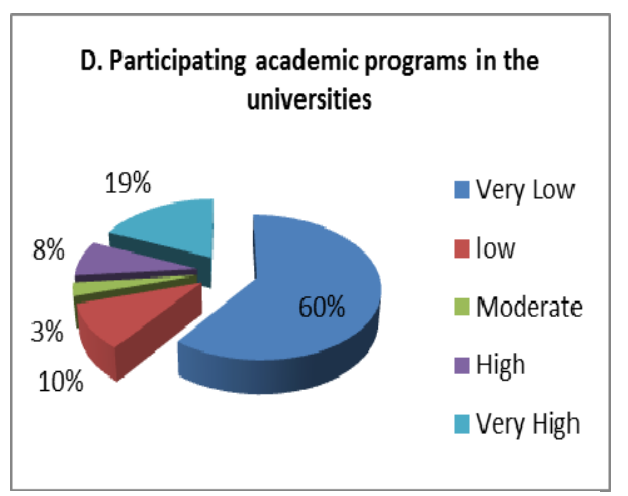

Figure no. 4. Participating academic programs in the universities

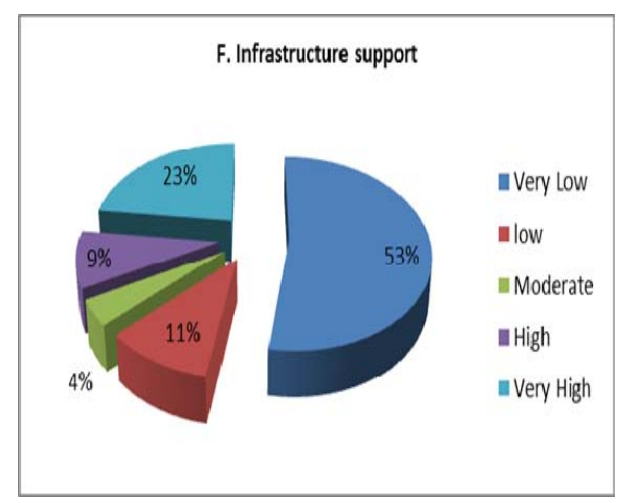

Figure no. 6. Infrastructure support 


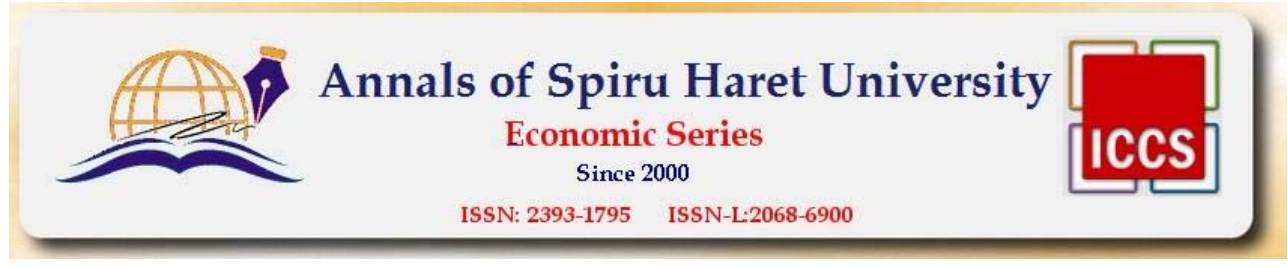

Issue 1/2018

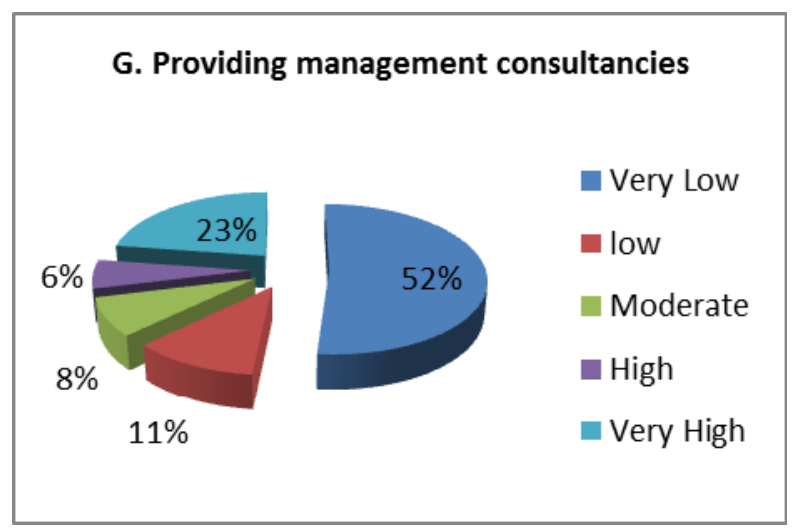

Figure no. 7. Providing management consultancies

The focus group discussion conducted after the survey revealed several policy implications for establishing good relationships among universities and industries. They felt that universities are far away from the industry and many of the SMEs did not recognize what universities can do for their innovation. Intermediaries such as technology centres, business development centres and incubators [Galli \& Tuebal, 1997; Intarakumnerd \& Virasa, 2002] may represent some forms of opening up mechanisms to SMEs for triggering their innovations, by spreading the necessary knowledge, although they are almost nonexistent. The availability of financial institutions and the widespread spread of all communities are appreciated, but it is understandable that there is a problem with the role and attitude of the people in the frontline. SMEs representatives revealed their concern about the frontline officers with regard to their incompetence, poor innovative orientation and having neither real intention nor practical knowledge to provide an effective service. This sector needs a more practical mechanism to implement government decisions and policies more realistically while being context-sensitive.

In addition, they raised several considerations for promoting innovations through collaborations. Protection of domestic producers with international suppliers, support to find out the market places in the global market, providing common innovative infrastructure facilities, assistance and proximity to the universities and research firms are also among the expectations of SMEs for triggering their actions towards innovation. Further, they are now struggling with the problem of finding new and skilled labour force for their industries, as many young people with fresh knowledge gathered from technical colleges and universities prefer to find foreign 


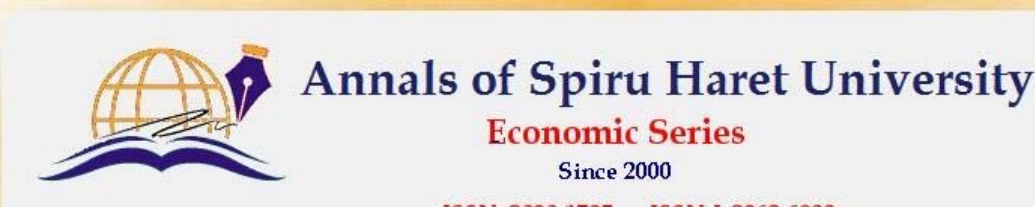

ISSN: 2393-1795 ISSN-L:2068-6900

\section{Issue 1/2018}

employment with prospects of high salaries or to join large firms with prestigious names instead of working in SMEs. Therefore, recruitment of new and young employees, which is directly linked to the absorptive capacity of a firm, is a difficult task for the emerging SMEs. This foreign employment policy has caused to increase labour cost too. SMEs expect government intervention to solve this issue, through revising foreign employment policies rather than simply promoting the migration of physical labour for lower level jobs in other countries.

Second Survey: The validity of the dimensions used to measure the strengths of the relationships was ensured through the extensive literature survey as discussed in previous sections. In order to identify relationships between faculties / departments and industry firms, the reliability of the data collected has to be measured, since the questionnaire's reliability has been tested.

This relationship is measured on five dimensions;

1) the frequency of conducting joint research activities;

2) the frequency related to inviting the personnel for visiting lecturing for the faculty/departments;

3) the degree of conducting the mutual joint research conference;

4) the frequency of conducting and engagement in workshops, meetings, training, and consultancies for the improvement of skills and knowledge sharing;

5) the frequency of sharing research and development infrastructure with each other.

The sample adequacy was measured using the factor analysis. "KMO and Bartlett's Test" was used as the benchmark and the outcome indicated a value of 0.752 , which was greater than 0.5 , thus it was determined that the sample is adequate. After that, the reliability analysis was conducted for the responses received on perceived dimensions on university industry relationships. The reliability is proven with the calculated Cronbach score of 0.846, which is greater than 0.7. The questions included in the questionnaire sufficiently presented the relationships that exist among faculties/departments with firms representing the industry.

This research study attempted to explore the networking relationships that exist among universities and industries in the NIS in developing countries. Following the survey methodology, the data were collected about the network relationships among the universities, the science and technology institutions and the firms in the industries, though the present study is focusing only on the university-industry relationships. We have succeeded in collecting 104 completed questionnaires to reveal the relationships maintained by each department and 

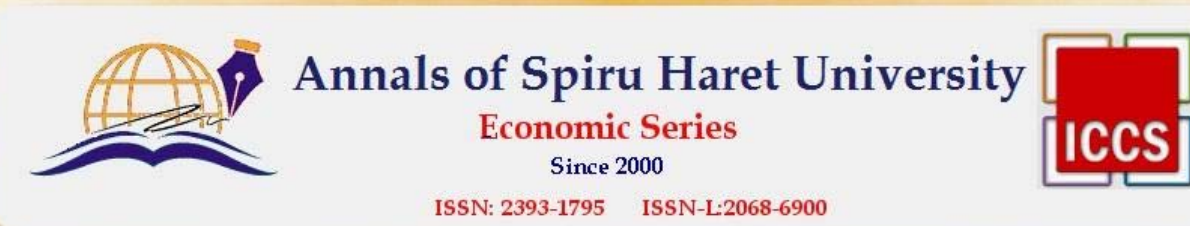

Issue 1/2018

faculty over five dimensions identified and we used SNA methodology to graph and measure the collected data.

These partnerships were analyzed with the strength of relationships across each dimensions. Summary statistics and standard drawings were used to identify and measure strength of the relationships using NodeXL application software. However, there is no sufficient number of relationships found between the departments/faculties and the firms in the industry (Figure no. 8).

The departments or the faculties were requested to name the institutions and indicate the strength of such ties. There were limited networks that were revealed. The responded faculties / departments suggested a few numbers of firms in the university system. Hence, it can be concluded that there is a limited networking relationships that exist between the university sector and the firms in the industry. This finding is the confirmation of limited relationships revealed in the first survey conducted for identifying the innovative behaviour of SMEs in the industries.

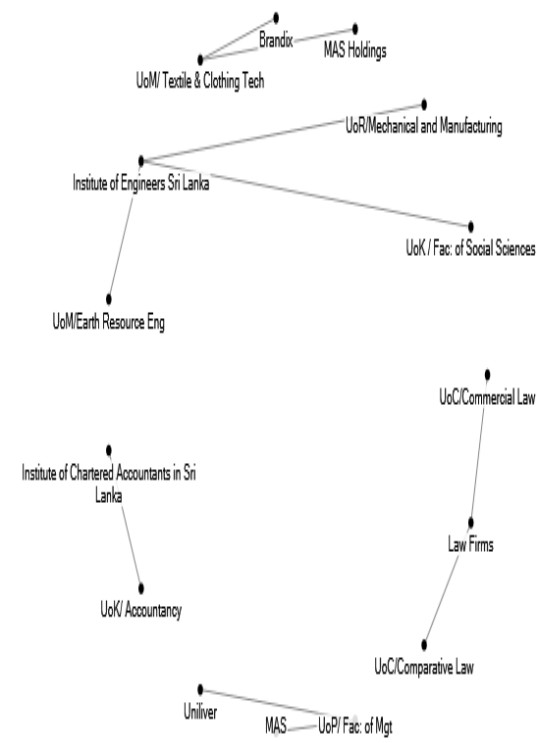

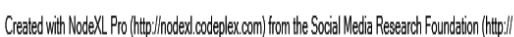
www.sminfundation.org)

\begin{tabular}{|l|r|l|r|l|r|r|r|}
\hline & $\begin{array}{l}\text { Any } \\
\text { kind of } \\
\text { links }\end{array}$ & $\begin{array}{l}\text { Joint } \\
\text { leesearc } \\
\text { ll }\end{array}$ & $\begin{array}{l}\text { Visiting } \\
\text { lecturin } \\
\text { g }\end{array}$ & $\begin{array}{l}\text { Joint } \\
\text { Conferere } \\
\text { nces }\end{array}$ & $\begin{array}{l}\text { worksh } \\
\text { ops, } \\
\text { training }\end{array}$ & $\begin{array}{l}\text { Sharing } \\
\text { R\&D } \\
\text { infl'a }\end{array}$ \\
\hline Graph Type & \multicolumn{7}{|c|}{ Undirected } \\
\hline Vertices & 15 & 12 & 15 & 13 & 15 & 10 \\
\hline Unirque Edges & 10 & 8 & 10 & 8 & 10 & 7 \\
\hline Edges With Duplicates & 0 & 0 & 0 & 0 & 0 & 0 \\
\hline Total Edges & 10 & 8 & 10 & 8 & 10 & 7 \\
\hline
\end{tabular}

\begin{tabular}{|l|r|r|r|}
\hline Firms & Degree & $\begin{array}{l}\text { Betweenness } \\
\text { Centrality }\end{array}$ & $\begin{array}{l}\text { Closeness } \\
\text { Centrality }\end{array}$ \\
\hline Institute of Engineers Sri Lanka & 3 & 3.000 & 0.333 \\
\hline Law Finms & 2 & 1.000 & 0.500 \\
\hline UoP/ Fac: of Mgt & 2 & 1.000 & 0.500 \\
\hline UoM/ Textile \& Clothing Tech & 2 & 1.000 & 0.500 \\
\hline Uoc Commercial Law & 1 & 0.000 & 0.333 \\
\hline UoC Comparative Law & 1 & 0.000 & 0.333 \\
\hline
\end{tabular}

Figure no. 8. Network Relationship among Departments/Faculties in the University Sector and National R\&D Institutes 


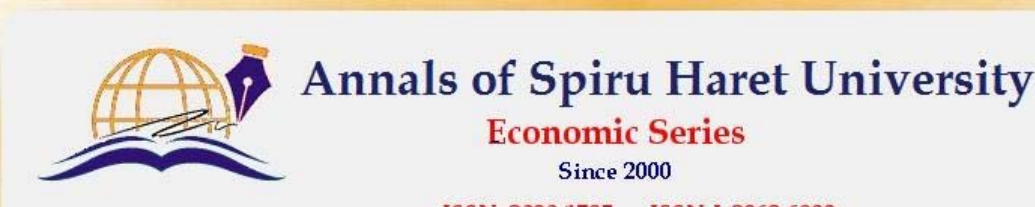

ISSN: 2393-1795 ISSN-L:2068-6900

Issue 1/2018

\section{Interviews conducted with Vice Chancellors}

The study was planned to access and interview all the Vice Chancellors of the national universities in Sri Lanka. However, it was possible to reach only seven Vice Chancellors for reasons of some limitations in their busy schedules and the remoteness of their locations from Colombo. The first four universities, the University of Moratuwa, the University of Sri Jayewardenepura, the University of Peradeniya, and the University of Kelaniya are long established universities, while the other three universities are relatively young. The University of Moratuwa is mainly specialized in engineering and technology, while other three universities are well-known establishments for many disciplines. The University of Sri Jayewardenepura is the largest among other in terms of student enrolment, while the University of Peradeniya is the oldest university in the country. Rajarata University of Sri Lanka and Sabaragamuwa University of Sri Lanka have been established in 1996 granting university status merging to the university colleges affiliated with the technical colleges in different provinces and these are located about $200 \mathrm{~km}$ away from Colombo city. Wayamba University of Sri Lanka is even younger than other universities because it was established in 1999 awarding the university status for the Wayamba University College, which operated under Rajarata University of Sri Lanka previously.

All the seven Vice Chancellors emphasized that the role of universities is not only limited to traditional teaching and learning, but also inwardly oriented to researching and administrating internal matters. There is a tendency for thinking now on more collaborative work with external institutions and the industry to ensure the independency of the university and the expanding boundaries of the universities adapting to the global trends. The Vice Chancellors stressed the importance of collaborative research activities and working more closely with the social milieu and economic needs of the country, though there are some structural and cultural barriers to surmount with the traditional mode of universities. Hence, all Vice chancellors accepted the structural and financial flexibility needed for being competitive in the modern changing and more challenging environment.

The interviews aimed at revealing the interconnectedness of the universities with the industries for the purpose of developing new products, processes and other solutions through collaborative engagement in $R \& D$ projects. At the interviews, it transpired that the established universities have a good potential with their capabilities to bridge the gap prevailing between the present level of collaborations and required level for effective process of innovation. However, it is revealed that the existing relationships are not sufficient to exploit maximum capabilities of the 40 


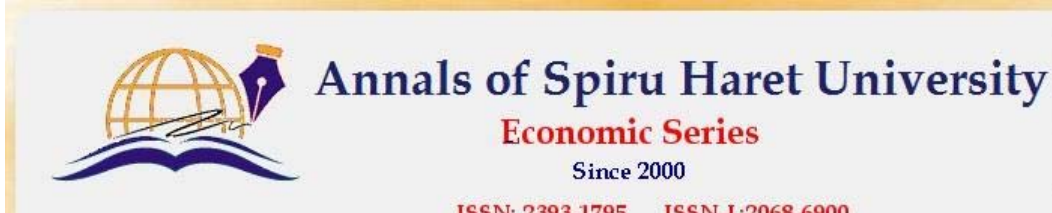

ISSN: 2393-1795 ISSN-I-2068-6900

Issue 1/2018

university sector and the industrial sector. The University of Moratuwa has shown its forwardness in this area engaging with several MoUs with industrial firms and has engaged in establishing a few collaborative incubators to joint research activities. The University of Peradeniya and the University of Kelaniya have also benefitted from such collaborations. However, other four universities have not revealed that there is a considerable number of such engagements. Many engagements are found at individual level, instead they are maintained at institutional level. Hence, the data were not available in the university level in this regard.

Collaborations with industries are limited mainly because of internal and external matters as revealed in the study. Speaking about the academics' heavy workload in teaching and internal orientation, teaching is considered as their main role. Hence, it is the main internal barrier for exposure to the external world. The academics have functioned as good teachers in the university system for a long period of time despite difficulties in the transition of the traditional role to a new R\&D oriented role of the academic. This favorable internal culture has been continually emphasized in interviews, reiterating the felt need to change this existing nature of internal culture for a better innovative performance in the future. The other main problem is the industry's hesitation in collaborating with the university sector, as a result of their lack of trust and lack of R\&D orientation, lack which was brought into focus in the interviews. There is still no sufficient attention paid by the industrial firms towards active engagement of R\&D. Most firms in Sri Lanka have shown their interest in just surviving in the present markets instead of looking forward to being more competitive through innovation. Hence, this demand factor limits such successful collaborations between the two sectors.

However, the Vice chancellor of the University of Peradeniya, despite its location away from the main capital city, firmly mentioned that many factors are acting positively for this kind of collaborations. He mentioned further that the trust of the industry on the R\&D capabilities of the University is the key factor to attract $\mathrm{R} \& \mathrm{D}$ research projects from the industries. It seems this university enjoys the benefits of being a long established university in the country. This issue is of such importance and influence because of their forte of endowment, participating and genius in all the disciplines and having the largest multi-disciplinary faculty members in the country. It is a matter of fact that their reputation is predominantly built upon these issues and the external firms are eager to establish relationships and invest funds on R\&D projects.

The most noticeable and important collaborative attempts between universities and industries are seen in the field of student internship programs. All universities are 


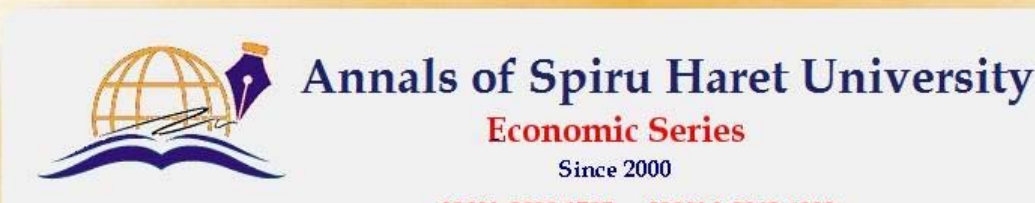

ISSN: 2393-1795 ISSN-L:2068-6900

\section{Issue 1/2018}

seeking the partnerships from the industry to improve and ensure their graduate employability through strong internship programs. There are very good formal mechanisms in some universities for their graduate training aims and objectives though there is only a little standing on research and development domains. Such attempts can be effectively used to reduce the gap between the two sectors, the industry and the university, and build trust on each other.

These results are confirmed with the interview data obtained through interviewing Vice Chancellors. Further, it was found that there is a good tendency in allocation of resources towards innovation infrastructure and trend in establishing effective networking relationships. The weak relationships found among the universities, the S\&T Institutions and the firms were justified with the limited resources available in the university sector, restricted to mode one mission, prevailing culture among university staff and students and lack of consistency of the government policies on education system of the country. Most of universities are still define their role is primarily facilitation of knowledge sharing and learning, hence tagged as teaching universities. It was emphasized the importance of active engagement of the university sector by deploying more resources for innovation, encouraging academic members to engage in collaborative research activities which will address the practical issues of the industries to bridge the gap between the expected innovative performance of the university sector and the actual performance. This study indicates the importance of establishing strong partnerships among universities, S\&T institutions and the firms representing industries, Universities are requested to play leading role to connect the knowledge creation process and facilitating firms to commercialize created knowledge collaboratively.

\section{Conclusion}

This study focused on identifying existing collaborations between universities and the firms in Sri Lanka in order to promote innovations for the economic and social benefits. There was little intention and intervention in both parties engaged in joint activities as revealed in both surveys and the interviews conducted with Vice Chancellors of the Universities. It is revealed that many universities in Sri Lanka still highly focus on teaching, especially undergraduate teaching in mass scale offering job oriented highly sought after degree programs. This traditional system helps to create graduates demanded by the multinational and large incumbent organizations and this is the role of the university and higher education system, which is considered as taken for, granted. There is a tendency towards entrepreneurship and innovation among many university leaders but the present level of resource deployment and 


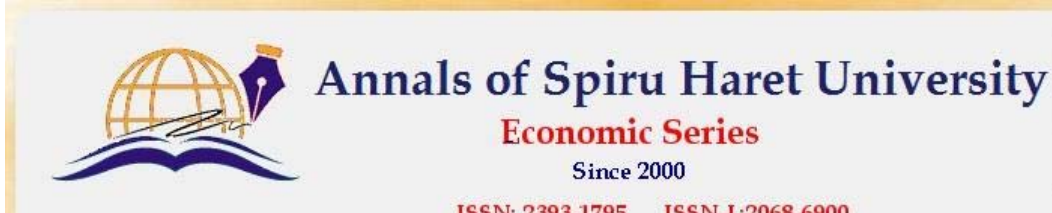

ISSN: 2393-1795 ISSN-I-2068-6900

Issue 1/2018

motivation is not up to the satisfied level. Academics mainly do research activities for their own profiles. Collaborative industry based research activities are rare in many areas though agriculture and some science based collaborations exist. The main interlink between the industry and the academia is conducting internship programs. Both parties are keen on this matter as there are mutual benefits from internship programs. Apart from that these two sectors are highly fragmented and engaged in their activities isolated as explained in Helix II [Etzkowitz \& Leydesdroff, 2000] and S1 [Galli \& Teubal, 1997].

This study reveals that the SMEs in Sri Lanka are still reluctant to come to the university sector to borrow new knowledge and technologies for the application in improvements of their products and processes due to their unawareness on the university role in this regard. Further, industry does not believe that university can help to solve their industrial issues though this sector is facing huge vacuum of new and updated knowledge. SMEs perceive that it is unnecessary to the firms and is difficult to recover the investment for innovation with the restricted market conditions. They amend to their perception with the belief on the role of universities that these universities are there for producing advanced level knowledge workers matched with incumbent large firms. On the other hand, almost $50 \%$ of university academics still work only in their traditional teaching role showing the characteristics of the single role academics as mentioned in De Silva et al (2012). The Vice Chancellors of the universities pointed out that it is very difficult to transform existing inward oriented culture in the national universities exist though there are new avenues and opportunities opened with the flexible policies of the government. It is emphasized that the presence of universities highly independent and secured without private partnerships mainly continuous funding from the government to the survival of the university system. This funding from the government is mainly dedicated for producing employable undergraduates and it is considered as a mandatory requirement resulting with university teachers opt to believe that teaching is their main responsibility. The performance evaluation system of the university teachers has also based on the assessment of teaching performance with little emphasis on research activities.

However, there are positive trends between universities and large organizations especially in collaborative research activities, product developments and developing process technologies. A few incubators are available which share and develop infrastructure and resources combined by the universities and industries. Further, government allocation for higher education sector is not sufficient at present as a result of prioritizing other development targets. Hence, universities need to self-rely 


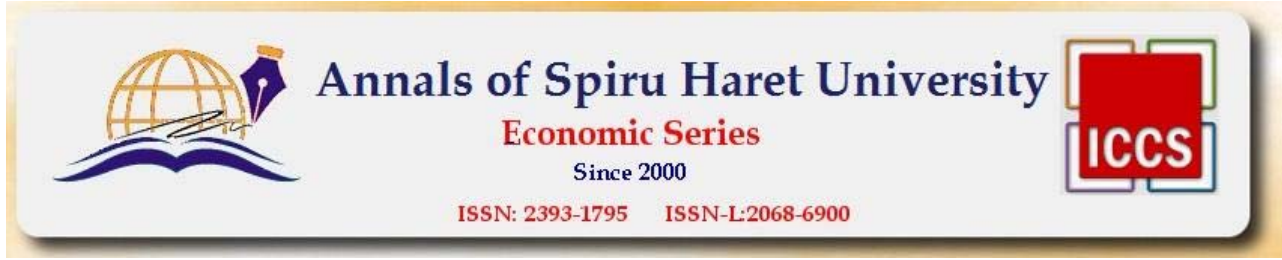

\section{Issue 1/2018}

through innovative fund sources to be independent from limited government allocations while promoting entrepreneurial activities among the university community. This will urge academics and students to work more collaboratively with the outside funding, mainly with industries. Strengthening networking relationships through government intervention and policy deployment will be required for the effective and efficient work of this systematic view.

\section{References}

1. Chesbrough, H.W., Open Innovation: The New Imperative for Creating and Profiting from Technology (Boston, MA: Harvard Business School Press, 2006).

2. Cohen, L. R. \& Noll, R. G., "Privatizing Public Research”, Scientific American, (1994): 271-273.

3. De Silva, L. R., Uyarra, E. \& Oakey, R., "Academic Entrepreneurship in a ResourceConstrained Environment: Diversification and Synergistic Effects”, Technology Transfer in a Global Economy, (2012):73-97

4. Etzkowitz, H. \& Leydesdorff, L., "The Dynamics of Innovation: from National Systems and Mode 2 to a Triple Helix of University-Industry-Government Relations", Research Policy, 29 (2000): 109-123.

5. Feinson, S., "National Innovation Systems Overview and Country Cases," Knowledge Flows and Knowledge Collectives: Understanding the Role of Science and Technology Policies in Development, (2003): 13-38.

6. Fleming, L. \& Sorenson, O., "Science as a Map in Technological Search", Strategic Management Journal, 25(8-9) (2004): 909-928.

7. Freeman, C., Technology Policy and Economic Performance: Lessons from Japan (London, Frances Pinter, 1987).

8. Galli, R. \& Tuebal, M., Paradigmatic Shifts in National Innovation Systems (1st ed.), (1997), http://ifise.unipv.it/Publications/Paradigmatic.pdf, Accessed July 05, 2015.

9. Geuna, A. \& Muscio, A., "The Governance of University Knowledge Transfer: A Critical Review of the Literature”, Minerva, 47(1) (2009): 93-114.

10. Hargadon, A., "Brokering Knowledge: Linking Learning and Innovation”, Research in Organizational behavior (1st ed.), 24 (2002): 41-85.

11. Intarakumnerd, P. \& Virasa, T., "Broader Roles of RTOs in Developing Countries: From Knowledge-Creators to Strengtheners of National Innovation System” (2002), http://www.cid.harvard.edu/archive/biotech/events/sti_conf/intarakumnerd200902.pd f, Accessed January 05, 2015.

12. Klevorick, A., Levin, R., Nelson, R. \& Winter, S., "On the Sources and Significance of Inter-Industry Differences in Technological Opportunities”, Research Policy, 1st ed., (1995): 185-205. 

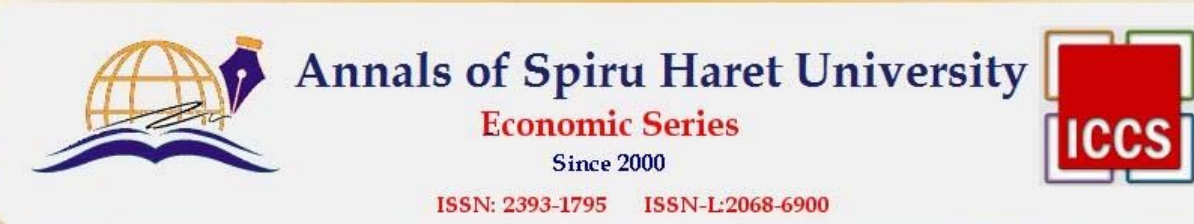

ISSN: 2393-1795 ISSN-I-2068-6900

Issue 1/2018

13. Lundvall, B., "User-producer relationships, national systems of innovation and internationalization", National Systems of Innovation: Towards a Theory of Innovation and Interactive Learning (1st ed.), (1992): 45-67.

14. Lundvall, B. Å. (Ed.), National Systems of Innovation: Toward a Theory of Innovation and Interactive Learning (Vol. 2), (Anthem Press, 2010).

15. Munari, F., \& Toschi, L., "Do Venture Capitalists Have a Bias against Investment in Academic Spin-offs? Evidence from the Micro and Nanotechnology Sector in the UK”, Industrial and Corporate Change, 20(2), (2011): 397-432.

16. Nelson, R. R. (Ed.), National Innovation Systems: A Comparative Analysis (Oxford University Press, 1993).

17. OECD, National Innovation Systems (Paris, 1997).

18. Perkmann, M. \& Walsh, K., "University-Industry Relationships and Open Innovation: Towards a Research Agenda”, International Journal of Management Reviews, 9(4), (2007): 259-280.

19. Rosenberg, N., “Why Do Firms Do Basic Research (with their own money)?”, Research policy, 19(2), 165-174.

20. Scott, J., “Social network analysis”, Sociology, 22(1) (1988):109-127.

21. University Grant Commission, University Statistics Book (published by UGC Sri Lanka 2015).

22.Van Looy, B., Ranga, M., Callaert, J., Debackere, K. \& Zimmermann, E. “Combining Entrepreneurial and Scientific Performance in Academia: Towards a Compounded and Reciprocal Matthew-effect?”, Research Policy, 33(3) (2004): 425-441. 
